All of this is good news for biotech. There is always concern when the sector is awash in money that some of the bets are bad, and when they implode, the funding environment will collapse with it. But science and money are intertwined, and biotech needs both. The 154 A rounds in 2017 are 154 new companies chasing down disease, and they weren't there a year ago.

Stephen Knight, president and managing partner of F-Prime Capital Partners, worked with ARCH Venture Partners to seed, found and launch Denali with its monstrous \$217-million series A round. Working with builders like Atlas and ARCH means F-Prime "probably helped supercharge" the trend of high A rounds, he says, adding that "most of the groups we work with want to build things that are real."

But investors follow the money, and certainly some in biotech are there less for the science and more for the returns. These days it's not easy to know who is who. Perhaps the crossover investors and hedge funds that are newly playing with company creation are doing it because they understand the benefit it can bring to patients. Or, perhaps they want the returns early-stage building can bring.

"That's one of those things," Knight says. "When the tide goes out, we'll find out."

Note: Any Supplementary Information and Source Data files are available in the online version of the paper.

\title{
PODCAST
}

\section{First rounders: John Maraganore}

John Maraganore is CEO of Alnylam Pharmaceuticals. In his talk with Nature Biotechnology, he discusses his decade at Biogen, running an RNAi company when skepticism covered the field, and growing up the son of Greek immigrants in Chicago. http://www.nature.com/nbt/podcast/index.html

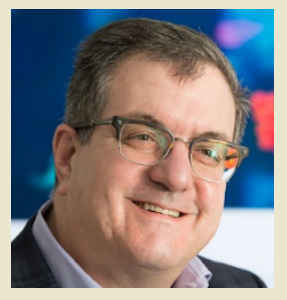

